\title{
The Association Between Systemic Inflammatory Markers and Post-Stroke Depression: A Prospective Stroke Cohort
}

\author{
Jingjie $\mathrm{Hu}^{*}$ \\ Liuyuan Wang* \\ Kaili Fan \\ Wenwei Ren \\ Qiongzhang Wang \\ Yiting Ruan \\ Chengxiang Yuan \\ Guiqian Huang \\ Jincai $\mathrm{He}$
}

Department of Neurology, The First Affiliated Hospital of Wenzhou Medical University, Wenzhou, 325000, Zhejiang, People's Republic of China

*These authors contributed equally to this work

\begin{abstract}
Objective: Inflammation plays an important role in stroke. Many inflammatory markers in peripheral blood are proved to be associated with stroke severity or prognosis. But few comprehensive models or scales to evaluate the post-stroke depression (PSD) have been reported. In this study, we aimed to compare the level of systemic inflammation markers between PSD and non-PSD patients and explore the association of these inflammatory markers with PSD.
\end{abstract}

Methods: Totally, 432 ischemic stroke patients were consecutively enrolled in the study and received 1 month follow-up. We used the 17-Hamilton Rating Scale to measure depressive symptoms at 1 month after stroke. With the Hamilton Depression Scale score of $>7$, patients were diagnosed with PSD. Systemic immune-inflammation index (SII), neutrophil-tolymphocyte (NLR), platelet-to-lymphocyte (PLR) and derived neutrophil-to-lymphocyte ratio (dNLR) were calculated from the admission blood work.

Results: Finally, 129 patients $(30.5 \%)$ were diagnosed with PSD at 1 month. PSD patients showed significantly higher levels of SII (501.27 (345.43-782.58) vs 429.60 (315.64570.98), $\mathrm{P}=0.001)$, NLR (2.36 (1.77-3.82) vs 2.17 (1.56-2.80), $\mathrm{P}=0.010)$, dNLR (1.67 (1.30-2.51) vs 1.54 (1.16-1.99), $\mathrm{P}=0.009)$, PLR (124.65 (95.25-155.15) vs 109.22 (92.38142.03), $\mathrm{P}=0.015)$, especially $\mathrm{SII}$ at admission as compared to non-PSD patients. In the logistic analysis, SII value $(>547.30)$ was independently associated with the occurrence of PSD $(\mathrm{OR}=2.181,95 \% \mathrm{CI}=1.274-3.732, \mathrm{p}=0.004)$, better than $\mathrm{dNLR}(\mathrm{OR}=1.833,95 \%$ $\mathrm{CI}=1.071-3.137, \mathrm{p}=0.027), \mathrm{PLR}(\mathrm{OR}=1.822,95 \% \mathrm{CI}=1.063-3.122, \mathrm{p}=0.029)$ and NLR (OR $=1.728,95 \% \mathrm{CI}=1.009-2.958, \mathrm{p}=0.046)$.

Conclusion: Increased SII, PLR, dNLR, NLR, particularly SII at admission, are significantly correlated with PSD and may add some prognostic clues to find early discovery of PSD.

Keywords: inflammatory markers, post-stroke depression, systemic immune-inflammation index, neutrophil-to-lymphocyte, platelet-to-lymphocyte, derived neutrophil-to-lymphocyte ratio

\section{Introduction}

Stroke is a multifactorial disease with high mortality and morbidity. There are approximately 3 million new strokes every year in China. ${ }^{1,2}$ It is well acknowledged that stroke can lead to pretty much further complications, such as cognitive impairment, disability, mental disorders and so on. ${ }^{3-5}$

Post-stroke depression (PSD) is strongly associated with further worsening of physical and cognitive recovery, functional outcome and quality of life. ${ }^{6}$ A meta-analysis of 
61 studies by Hackett and Pickles ${ }^{7}$ reported a pooled frequency of depression of $31 \%$ at any time up to five years following stroke, consistently with results found in a 10-year earlier review where the pooled frequency was $33 \%{ }^{8}$ Depression negatively affects patients' ability to engage in rehabilitation therapies. This emphasises the need of better evidence-based strategies of screening, prevention and therapy for PSD patients. Indeed, PSD remains relatively underdiagnosed, under-treated and under-researched. Despite of numerous clinical and experimental studies have been done, the pathophysiological mechanisms of PSD remain far from clear. The available evidence supports the reciprocal modulation of neurotransmitter systems, neuroinflammation, neuroendocrine activation, neuronal plasticity, vascular factors which may take effect in recognizing the disease process. ${ }^{9,10}$

Several studies proved that patients developed a storm of inflammation in the body after stroke. ${ }^{11-14}$ Extensive investigations also suggested that high levels of pro-inflammatory and inflammatory markers were involved in the inflammatory response to depression, including interleukin-1, interleukin18 , interleukin- 6 and tumor necrosis factor- $\alpha$ (TNF- $\alpha$ ), interferon- $\gamma$ (IFN- $\gamma) .{ }^{15,16}$ Thus, researchers suspected whether inflammation was related with the occurrence of PSD and have confirmed this by animal experiments. ${ }^{17}$ In recent years, cell counting and their combinations such as neutrophilto-lymphocyte (NLR), platelet-to-lymphocyte (PLR), derived neutrophil-to-lymphocyte ratio (dNLR) as classic hematological markers of systemic inflammation, were reported to be able to reflect sensitively the inflammatory response. ${ }^{18,19}$ Those indexes, derived from peripheral blood tests are easily available, have been validated to have a certain diagnostic value in a variety of tumors, coronary atherosclerotic heart disease, stroke and so on. ${ }^{20-22}$ Besides, previous studies found increased NLR, PLR were associated with the prevalence and poorer outcome of post-stroke depression. ${ }^{23,24}$ More recently, systemic immune-inflammation index (SII), a new Inflammatory biomarker, was constructed based on neutrophil, lymphocyte, and platelet count. As an easy-to-obtain indicator, the ratio of SII has been a research hotspot in diagnosing or predicting diseases, such as cardiovascular diseases, infections, inflammatory diseases, psychosis and several types of cancers. ${ }^{25,26}$ SII was first developed by $\mathrm{Hu}$ and expected to predict prognosis of hepatocellular carcinoma after surgery. ${ }^{27}$ Hu's study demonstrated that the prediction ability of SII was more sensitive than those methods that use only one or two cell subtypes on hepatocellular carcinoma. Because inflammation plays a vital role in many diseases, now, there is continued interest in the inflammatory process in cerebrovascular disease. Hou's study showed SII was associated with severity of acute ischemic stroke and might be more reasonable and effective in the evaluation of stroke than NLR and PLR. ${ }^{28}$ Gabriela reported SII predicted poor outcome after spontaneous supratentorial intracerebral hemorrhage. ${ }^{29}$ There have been several studies about SII and psychiatric disorders, especially depression. Mazza found a tight correlation between baseline SII and scores of depression and anxiety in COVID19 survivors at follow-up. ${ }^{30}$ A single study revealed higher SII levels were linked to poor prognosis in major depressive disorder, ${ }^{31}$ suggesting that it could be a marker of the lowgrade inflammation observed in mood disorder. ${ }^{32,33}$

To the best of our knowledge, the relationship between SII and PSD has not been reported to date. We aimed to investigate whether the levels of SII, as well as NLR, PLR and dNLR were associated with the occurrence, development and severity of disease in patients with PSD. We hypothesized that SII could better reflect the inflammatory status than other inflammatory markers in PSD.

\section{Materials and Methods Subjects}

All acute ischemic stroke patients were from the Stroke Ward of the First Affiliated Hospital of Wenzhou Medical University, between 2014 and 2017. Four hundred and eighty-six patients consecutively participated in our study. The inclusion standards were: (i) patients aged between 18 and 80 years old, (ii) first-ever acute ischemic stroke happening within seven days at admission, (iii) diagnosed by computed tomography (CT) or magnetic resonance imaging (MRI), (iv) patients willing to sign the written informed consent. The exclusion standards were: (i) severe psychiatric history especially depression, (ii) any central nervous system disease, such as a diagnosis of dementia, Parkinson's disease or other significant cognitive impairment before stroke, (iii) the use of depression drugs, (iv) serious aphasia or dysarthria or hearing impairment or chronic inflammatory disease that might influence examination, (v) intracerebral hemorrhage, (vi) a history of stroke, (vii) severe heart, respiration, renal disease or cancer, (viii) patients that could not cooperate with us to complete a series of assessment.

\section{Clinical Measurement}

Demographic characteristics (age, gender, education, etc.), vascular risk factor (hypertension, diabetes mellitus, hyperlipidaemia, coronary heart disease, etc.), and 
TOAST subtypes. The severity of stroke was assessed by experienced neurologists using the National Institutes of Health Stroke Scale (NIHSS) within 24h of admission. Functional outcomes were evaluated by the modified Rankin Scale (mRS) and Activities of Daily Living (ADL) at 1 month.

\section{Psychological Measurement}

All patients were evaluated by the 17-item Hamilton Depression Scale (HAMD) ${ }^{34}$ at 1 month. Patients with HAMD score $>7$ were considered to be diagnosed poststroke depression according to the Structured Clinical Interview for the Diagnostic and Statistical Manual of Mental Disorders, 4th edition.

\section{Laboratory Tests}

All blood samples were collected by vacuum tubes the next morning (range: 05:00-08:00) after admission by trained nurses and tested by clinical laboratory technicians in a hospital certificated laboratory. White blood cell (WBC), neutrophil (N), lymphocyte (L), platelet (P) from the patients' first blood sampling were recorded after hospitalization. The formulas are as follows: NLR was calculated as neutrophil count/ lymphocyte count $(\mathrm{NLR}=\mathrm{N} / \mathrm{L})$, PLR was calculated as platelet count/lymphocyte count ( $\mathrm{PLR}=\mathrm{P} / \mathrm{L}$ ), dNLR was calculated as neutrophil count/ (leukocyte count - neutrophilcount) $(\mathrm{dNLR}=\mathrm{N} / \mathrm{N}-\mathrm{W})$ and SII was calculated as platelet count $\times$ neutrophil count/ lymphocyte count $(\mathrm{SII}=\mathrm{P} \times \mathrm{N} / \mathrm{L}){ }^{18,19,27}$

\section{Statistical Analyses}

All statistical analysis was performed by SPSS 23.0. Categorical variables were represented as frequency and percentages were compared using $\chi 2$ test. Continuous variables in normal distribution data described as means (SD) were compared using Student's $t$-test, whereas variables in non-normal distribution of data described as medians (quartiles) were compared using the Mann-Whitney $U$-test. Employing binary logistic regression analyzed the relationship between NLR, SII, PLR, dNLR and PSD when adjusted the confounding factors, such as age, gender, education, etc. $\mathrm{P}<0.05$ was considered statistically significant.

\section{Results}

\section{Patients' Characteristics}

A total of 423 patients with acute ischemic stroke were finally enrolled in the study (Figure 1). Among all follow- up patients, $272(64.3 \%)$ patients were male and the average age was $62.58 \pm 10.27$ years. The number of patients diagnosed with depression was 129 (30.5\%) 1 month later. Meanwhile, patients in the PSD group were predominantly male $(58 \%)$ and the average age was $62.0 \pm 10.9$ years. The proportion of current smokers was $18 \%$ and the average BMI was $24.35 \pm 3.31 \mathrm{~kg} / \mathrm{m}^{2}$. The baseline characteristics of the 423 patients with PSD and those without were summarized in Table 1. We found significant difference of SII (501.27 (345.43-782.58) vs $429.60 \quad$ (315.64570.98), $\mathrm{P}=0.001)$, NLR (2.36 (1.77-3.82) vs 2.17 (1.562.80), $\mathrm{P}=0.010)$, dNLR (1.67 (1.30-2.51) vs 1.54 (1.161.99), $\mathrm{P}=0.009)$, PLR (124.65 (95.25-155.15) vs 109.22 (92.38-142.03), $\mathrm{P}=0.015)$, WBC $(\mathrm{p}=0.012)$, Neutrophil $(\mathrm{p}=0.008)$ and Lymphocyte $(\mathrm{p}=0.022)$ between patients with and without PSD. The score of HAMD in the PSD group was higher than Non-PSD group (9 (10-13) vs 3 (15), $\mathrm{p}<0.001) 1$ month later. Moreover, there was a positive association between the SII levels and the HAMD scores ( $\mathrm{r}=0.160, \mathrm{P}=0.001)$. The PSD group had a more severe stroke with NIHSS $(3(2-6)$ vs.2(1-4), p<0.001) being higher at admission, as well as a worse functional outcome at 1 month with mRS $(2(1-3)$ vs $1(1-2), \mathrm{p}<0.001)$ being higher and the ADL being lower (95 (80-100) vs.100 (100-100), $\mathrm{p}<0.001)$. There was no obvious association between vascular risk factors, such as hypertension, diabetes mellitus, coronary heart disease, hyperlipidaemia and PSD. Stroke patients in small-artery occlusion seemed to be more susceptible to occur PSD.

\section{Predictors of the Occurrence of Depression}

We divided all patients into three subgroups according to tertiles of SII levels (tertile1, $<363.99 \times 10^{9} / \mathrm{L}$; tertile2, 363.99-547.30 $\times 10^{9} / \mathrm{L}$; and tertile3, $>547.30 \times 10^{9}$ /L). The demographics and diagnostic parameters of subgroup analysis are shown in Table 2. With stroke patients taken as a whole, tertile 1 taken as the reference and the presence of PSD taken as a dependent variable for SII values in the logistic analysis, higher SII values $(>547.30)$ remained independently associated with the occurrence of PSD (OR=2.181, 95\% CI $=1.274-3.732$, $\mathrm{p}=0.004)$. Using the same methods, similar conclusion could be attained in Table 3 when the dNLR $(\mathrm{OR}=1.833,95 \% \mathrm{CI}=1.071-3.137, \mathrm{p}=0.027)$ level was a continuous variable in the logistic regression analysis, as well as PLR $(\mathrm{OR}=1.822,95 \% \mathrm{CI}=1.063-3.122$, 


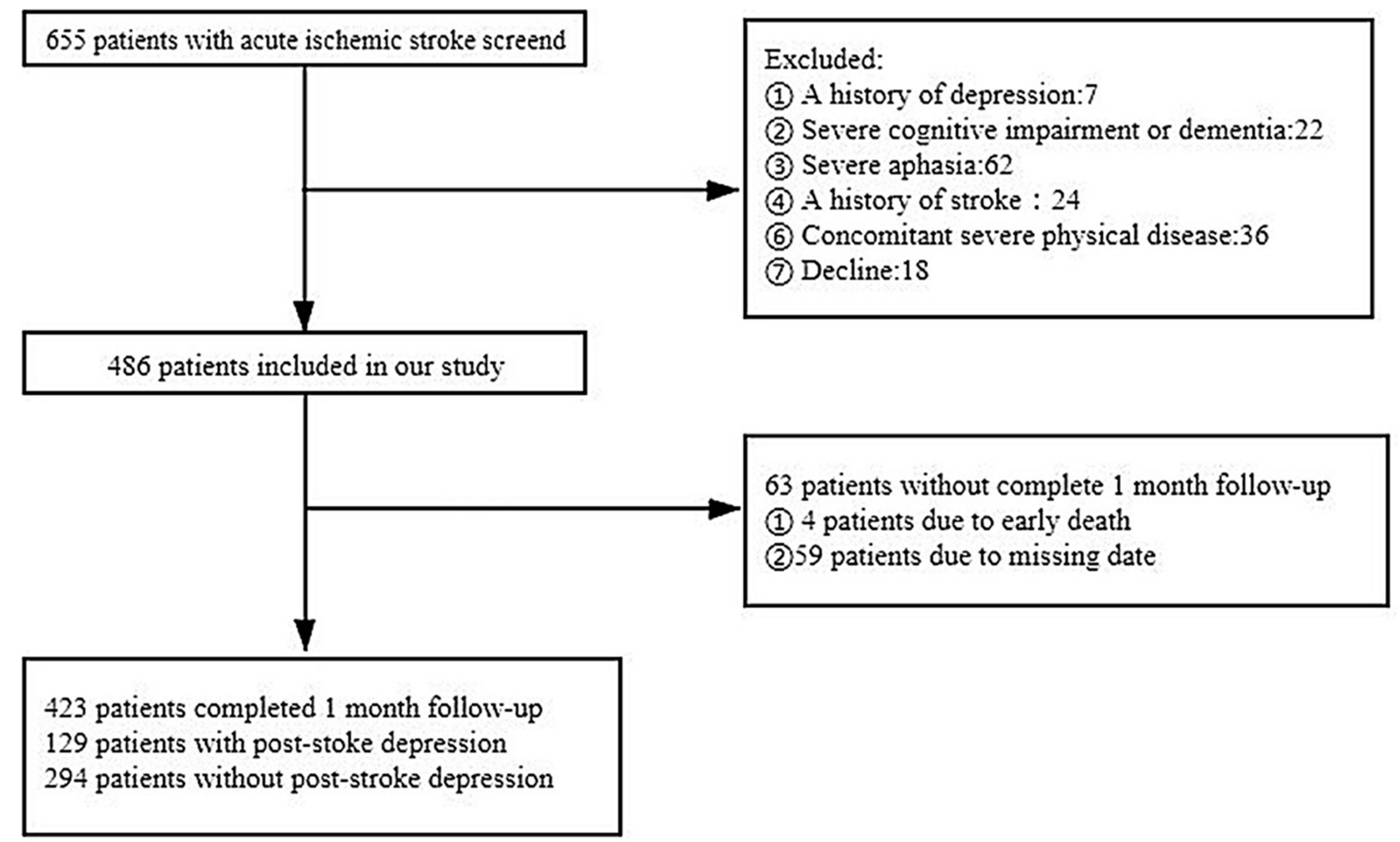

Figure I The process of screening patients in our study.

$\mathrm{p}=0.029)$ and NLR $(\mathrm{OR}=1.728,95 \% \mathrm{CI}=1.009-2.958$, $\mathrm{p}=0.046)$ after adjustment for confounding factors that had already been established as predictors of PSD in others studies and that significantly differed between two groups on the univariate analysis, including age, gender, educational year, baseline NIHSS, Coronary heart disease (Table 4). Apparently, SII has the maximum OR value above-mentioned inflammatory indexes.

\section{Discussion}

As far as we know, this is the first study to explore the connection between early elevated SII, dNLR and the occurrence and development of PSD. In our study, patients with PSD had higher SII, dNLR, NLR, PLR than patients without PSD, respectively. Patients with acute ischemic stroke showing high SII, dNLR, PLR, NLR were more likely to develop PSD, especially high SII after adjusting for confounders. Our results demonstrated that the SII was a better indicator of risk of the development of PSD compared with dNLR, NLR, PLR.

In this study, we finally found 129 (30.5\%) of acute ischemic stroke patients were diagnosed as depression 1 month later, which was in accordance with the results of previous studies. ${ }^{6}$ Furthermore, our study showed that PSD patients had poorer functional outcome and suffered more severe strokes. ${ }^{6}$ The correlation between NLR, PLR and PSD was also consistent with earlier studies. $^{23,24}$

PSD is a heterogeneous condition, and no single pathophysiological mechanism can fully explain PSD. According to some researches, ${ }^{35,36}$ one of the assumptions is that PSD is a multisystem inflammatory disease, both centrally and peripherally. Abnormal inflammatory response is linked to PSD. These inflammatory biomarkers alter neurotransmission and induce severe dysfunction in the brain. When acute ischemic stroke happens, neutrophils first migrate from peripheral blood vascular to the ischemic brain within a few minutes ${ }^{37}$ and release pro-inflammatory biomarkers, such as matrix metalloproteinases 9 (MMP9), cytokines (IL-6 etc), chemokines (MCP-1 etc), proteolytic enzyme, oxygen-free radicals and so on. ${ }^{38,39}$ These inflammatory mediators trigger a series of excitotoxic inflammatory response. At the same time, platelets aggregate in the point of lesion. Through combing with PSGL-1 and Mac-1, platelets cooperate with infiltrated neutrophils to activate platelet function and change the characteristics of endothelial cells, leading to more neutrophils to 
Table I Clinical and Demographic Characteristics of Participants

\begin{tabular}{|c|c|c|c|}
\hline $\begin{array}{l}\text { Baseline } \\
\text { Characteristics }\end{array}$ & $\begin{array}{c}\text { Non-PSD } \\
(n=294)\end{array}$ & $\begin{array}{c}\text { PSD } \\
(n=129)\end{array}$ & $\mathbf{P}$ \\
\hline \multicolumn{4}{|l|}{$\begin{array}{l}\text { Demographic } \\
\text { characteristics }\end{array}$} \\
\hline Male (\%) & $197(67)$ & $75(58)$ & 0.098 \\
\hline Age $(y)$, mean $\pm S D$ & $62.8 \pm 10.0$ & $62.0 \pm 10.9$ & 0.433 \\
\hline $\begin{array}{l}\text { Educational(y), mean } \\
\pm S D\end{array}$ & $4.4 \pm 4.3$ & $4.1 \pm 3.5$ & 0.527 \\
\hline $\operatorname{BMI}\left(\mathrm{kg} / \mathrm{m}^{2}\right)$, mean $\pm \mathrm{SD}$ & $24.25 \pm 7.85$ & $24.35 \pm 3.31$ & 0.919 \\
\hline \multicolumn{4}{|l|}{ Vascular risk factors (\%) } \\
\hline Hypertension & $214(72)$ & $94(73)$ & 1.00 \\
\hline Diabetes mellitus & $65(22)$ & $29(22)$ & 1.00 \\
\hline Coronary heart disease & $20(7)$ & $4(3)$ & 0.171 \\
\hline Hyperlipidaemia & $22(7)$ & $15(14)$ & 0.134 \\
\hline Alcohol consumption & $122(4 \mid)$ & $42(33)$ & 0.084 \\
\hline Current smokeing & $56(19)$ & $23(18)$ & 0.892 \\
\hline \multicolumn{4}{|l|}{ TOAST subtypes } \\
\hline LAA & $202(69)$ & $84(65)$ & 0.499 \\
\hline $\mathrm{CE}$ & $66(22)$ & $23(18)$ & 0.303 \\
\hline SAO & $26(9)$ & $22(17)$ & 0.019 \\
\hline \multicolumn{4}{|l|}{ Laboratory tests } \\
\hline WBC $\left(10^{9} / \mathrm{L}\right)$ & $6.6 \pm 1.8$ & $7.1 \pm 1.8$ & 0.012 \\
\hline Neutrophil (\%) & $60.3 \pm 9.2$ & $63.2 \pm 10.7$ & 0.008 \\
\hline Platelet $\left(10^{9} / \mathrm{L}\right)$ & $206.3 \pm 52.5$ & $215.8 \pm 55.1$ & 0.092 \\
\hline Lymphocyte (\%) & $28.9 \pm 8.4$ & $26.4 \pm 10.4$ & 0.022 \\
\hline \multicolumn{4}{|l|}{$\begin{array}{l}\text { Neuropsychological } \\
\text { function }\end{array}$} \\
\hline $\begin{array}{l}\text { NIHSS score media } \\
\text { (IQR) }\end{array}$ & $2(1-4)$ & $3(2-6)$ & $<0.001$ \\
\hline $\begin{array}{l}\text { mRS score at I month } \\
\text { media (IQR) }\end{array}$ & $I(I-2)$ & $2(I-3)$ & $<0.001$ \\
\hline $\begin{array}{l}\text { ADL score at I month } \\
\text { media (IQR) }\end{array}$ & $\begin{array}{l}100(100- \\
100)\end{array}$ & $95(80-100)$ & $<0.001$ \\
\hline $\begin{array}{l}\text { HAMD at I month } \\
\text { media (IQR) }\end{array}$ & $3(I-5)$ & $9(10-13)$ & $<0.001$ \\
\hline NLR media (IQR) & $\begin{array}{c}2.17(1.56- \\
2.80)\end{array}$ & $\begin{array}{c}2.36(1.77- \\
3.82)\end{array}$ & 0.010 \\
\hline PLR media (IQR) & $\begin{array}{l}109.22 \\
(92.38- \\
142.03)\end{array}$ & $\begin{array}{l}124.65 \\
(95.25- \\
155.15)\end{array}$ & 0.015 \\
\hline SII $\left(10^{\circ} / \mathrm{L}\right)$ media (IQR) & $\begin{array}{c}429.60 \\
(315.64- \\
570.98)\end{array}$ & $\begin{array}{c}501.27 \\
(345.43- \\
782.58)\end{array}$ & 0.001 \\
\hline dNLR media (IQR) & $\begin{array}{l}1.54(1.16- \\
1.99)\end{array}$ & $\begin{array}{c}1.67(1.30- \\
2.51)\end{array}$ & 0.009 \\
\hline
\end{tabular}

Notes: Data are presented as number of patients (\%) or median (interquartile range). Abbreviations: BMI, body mass index; LAA, large-artery atherosclerosis; CE, cardioembolism; SAO, small-artery occlusion; WBC, white blood cell; NIHSS, National Institutes of Health Stroke Scale; mRS, modified Rankin Scale; ADL, activities of daily living; IQR, interquartile range; SD, standard deviation.
Table 2 Baseline Characteristics of the Three Groups of SII

\begin{tabular}{|c|c|c|c|c|}
\hline & $\begin{array}{l}\text { Tertilel } \\
(n=\mid 4 I)\end{array}$ & $\begin{array}{l}\text { Tertile2 } \\
(n=\mid 4 I)\end{array}$ & $\begin{array}{l}\text { Tertile3 } \\
(n=\mid 4 I)\end{array}$ & $\mathbf{P}$ \\
\hline SII $\left(10^{9} / \mathrm{L}\right)$ & $<363.99$ & $\begin{array}{c}363.99- \\
547.30\end{array}$ & $>547.30$ & $<0.001$ \\
\hline Male (\%) & $84(60)$ & $97(69)$ & $91(65)$ & 0.270 \\
\hline Age $(y)$, mean $\pm S D$ & $62.2 \pm 10.6$ & $61.3 \pm 11.0$ & $64.3 \pm 8.9$ & 0.087 \\
\hline $\begin{array}{l}\text { Educational }(y) \text {, } \\
\text { mean } \pm S D\end{array}$ & $4.6 \pm 4.2$ & $4.6 \pm 4.5$ & $3.7 \pm 3.4$ & 0.143 \\
\hline $\begin{array}{l}\text { BMI }\left(\mathrm{kg} / \mathrm{m}^{2}\right), \text { mean } \\
\pm \mathrm{SD}\end{array}$ & $\begin{array}{r}25.18 \\
\pm 10.84\end{array}$ & $\begin{array}{l}24.21 \\
\pm 2.89\end{array}$ & $\begin{array}{r}23.40 \\
\pm 3.51\end{array}$ & 0.143 \\
\hline \multicolumn{5}{|l|}{$\begin{array}{l}\text { Vascular risk } \\
\text { factors (\%) }\end{array}$} \\
\hline Hypertension & $100(71)$ & $106(75)$ & $102(72)$ & 0.716 \\
\hline $\begin{array}{l}\text { Diabetes } \\
\text { mellitus }\end{array}$ & $33(23)$ & $37(26)$ & $24(17)$ & 0.162 \\
\hline $\begin{array}{l}\text { Coronary heart } \\
\text { disease }\end{array}$ & $10(7)$ & $10(7)$ & $10(7)$ & 1.00 \\
\hline Hyperlipidaemia & $13(10)$ & $12(9)$ & II (8) & 0.913 \\
\hline $\begin{array}{l}\text { Alcohol } \\
\text { comsuption }\end{array}$ & $50(35)$ & $56(40)$ & $58(4 I)$ & 0.596 \\
\hline Current smoking & $18(13)$ & $25(18)$ & $36(26)$ & 0.021 \\
\hline TOAST subtypes & & & & 0.094 \\
\hline LAA & 103(73) & $95(67)$ & $88(62)$ & \\
\hline CE & $27(19)$ & $33(23)$ & $29(21)$ & \\
\hline SAO & II (8) & $13(10)$ & $24(17)$ & \\
\hline $\begin{array}{l}\text { NIHSS score media } \\
\text { (IQR) }\end{array}$ & $2(1-4)$ & $2(I-4)$ & $3(1-5)$ & 0.193 \\
\hline
\end{tabular}

assemble in the brain edema region. ${ }^{40}$ Consecutive inflammatory reaction finally destroys the blood-brain barrier. Once the blood-brain barrier is damaged, our body will turn down the immune response in order to reduce the potential inflammation in the lesion. Lymphocytes also play an important role in inflammation, although the pathogenesis of lymphocytes might be controversial. Lymphocytes consisting of B and T cells, particularly CD4+, CD8+ T cells, can produce several cytotoxic substances and pro-inflammatory cytokines, nevertheless some researches report that lymphocytes have a protective effect towards inflammation. ${ }^{41}$ Stroke can also activate the pathway of the sympathetic nervous system, parasympathetic nervous system and hypothalamus pituitary adrenal axis, which induces the apoptosis of lymphocytes or transforms the percentage of lymphocytes. ${ }^{42}$ Those inflammatory and pro-inflammatory cytokines are thought to play an important role in the etiology of depression at the same time. ${ }^{15,16}$ It has been found that patients with 
Table 3 Factors Associated with PSD by Multivariate Logistic Regression Analysis

\begin{tabular}{|c|c|c|c|c|c|c|c|}
\hline & & \multicolumn{2}{|c|}{ Modell } & \multicolumn{2}{|c|}{ Model2 } & \multicolumn{2}{|c|}{ Model3 } \\
\hline & & OR(95\% Cl) & $\mathbf{p}$ & OR(95\% Cl) & $\mathbf{p}$ & OR(95\% Cl) & $\mathbf{p}$ \\
\hline \multirow[t]{2}{*}{ SII } & Int vs low & $0.927(0.540-|.59|)$ & 0.783 & $0.948(0.550-1.637)$ & 0.849 & $0.977(0.556-1.717)$ & 0.935 \\
\hline & High vs low & $2.099(1.266-3.478)$ & $0.004 *$ & $2.236(I .336-3.744)$ & $0.002 *$ & $2.181(1.274-3.732)$ & $0.004 *$ \\
\hline \multirow[t]{2}{*}{ NLR } & Int vs low & $0.573(0.346-0.951)$ & 0.031 & $1.052(0.6|7-1.79|)$ & 0.853 & $0.942(0.542-1.639)$ & 0.833 \\
\hline & High vs low & $0.594(0.359-0.984)$ & $0.043^{*}$ & $1.820(1.083-3.056)$ & $0.024 *$ & $1.728(1.009-2.958)$ & $0.046 *$ \\
\hline \multirow[t]{2}{*}{ PLR } & Int vs low & I.II5(0.657-I.892) & 0.686 & $1.096(0.644-1.864)$ & 0.735 & $1.055(0.607-1.833)$ & 0.850 \\
\hline & High vs low & $1.810(1.089-3.010)$ & $0.022 *$ & $1.845(1.101-3.091)$ & $0.020 *$ & $1.822(1.063-3.122)$ & $0.029 *$ \\
\hline \multirow[t]{2}{*}{$\mathrm{dNLR}$} & Int vs low & I.076(0.633-I.829) & 0.787 & I.I36(0.664-I.944) & 0.642 & $1.080(0.620-1.88 I)$ & 0.787 \\
\hline & High vs low & I.865(I.I23-3.099) & $0.016^{*}$ & $1.993(I .190-3.34 I)$ & $0.009 *$ & $1.833(1.07 \mid-3.137)$ & $0.027^{*}$ \\
\hline
\end{tabular}

Notes: Mode I was not adjusted for any variables. Model 2 was adjusted for age, gender and education years. Model 3 was adjusted for age, gender, education years, baseline NIHSS, Coronary heart disease. *Indicates statistically significant.

schizophrenia have increased levels of pro-inflammatory cytokines, such as IL1B, IL-6 and IL-8. ${ }^{43}$ In another study, pro-inflammatory cytokine levels were improved after antidepressant therapy. ${ }^{44}$ Depression increased leukocyte and neutrophil levels, while they decreased lymphocytes. ${ }^{45}$ Our research also testified that patients with depression after stroke had significantly higher level of white blood cell, neutrophils, platelets and lower lymphocytes than patients without depression.

However, there are still no exact biomarker to reflect inflammation in PSD up to now.
The blood routine test is a must-check examination for all patients admitted to the hospital. Inflammatory indexes can be obtained by simple calculation using existing items in the blood routine test. Thanks to the convenience and low price, inflammatory index have the potential to be widely used in clinic and have become a hot research field in recent year. A series of novel inflammatory factors measured in peripheral blood have provided useful information for predicting future events in several different clinical settings, mainly including NLR, dNLR, PLR, and SII. There is Chen's study

Table 4 Univariate Logistic Regression Analysis Factors Related to Severity of PSD

\begin{tabular}{|c|c|c|c|c|}
\hline \multicolumn{5}{|l|}{ Univariate Analysis } \\
\hline Variables & B & HR & $95 \% \mathrm{Cl}$ & P-value \\
\hline Sex & -0.380 & 0.684 & $0.447-1.047$ & 0.080 \\
\hline Age & -0.008 & 0.992 & $0.972-1.012$ & 0.432 \\
\hline Educational & -0.017 & 0.983 & $0.933-1.036$ & 0.527 \\
\hline BMI & 0.001 & 1.001 & $0.97 I-1.033$ & 0.937 \\
\hline Hypertension & -0.004 & 0.996 & $0.625-1.586$ & 0.987 \\
\hline Diabetes mellitus & -0.021 & 0.979 & $0.596-1.608$ & 0.933 \\
\hline Coronary heart disease & 1.109 & 3.302 & $1.306-8.873$ & $0.043 *$ \\
\hline Hyperlipidaemia & -0.537 & 0.585 & $0.291-1.175$ & 0.132 \\
\hline Alcohol comsuption & 0.385 & 1.469 & $0.95 I-2.27 \mid$ & 0.083 \\
\hline Current smoking & 0.081 & 1.084 & $0.634-1.855$ & 0.767 \\
\hline NIHSS score & 0.197 & 1.218 & $1.123-1.321$ & $<0.001 *$ \\
\hline SII & 0.390 & 1.478 & $1.140-1.915$ & $0.003 *$ \\
\hline NLR & 0.252 & 1.287 & $0.997-1.662$ & $0.053^{*}$ \\
\hline $\mathrm{dNLR}$ & 0.321 & 1.379 & $1.066-1.783$ & $0.014 *$ \\
\hline PLR & 0.304 & 1.355 & $1.048-1.752$ & $0.020 *$ \\
\hline
\end{tabular}

Notes: *Indicates statistically significant. 
showing the increased NLR at admission correlates with PSD and may help doctors get some prognostic information for the early discovery of PSD. ${ }^{23}$ Huang indicates PLR is a significant and independent biomarker to predict the development of PSD. ${ }^{24}$ In order to describe inflammatory reaction more comprehensively, SII adds platelet counts into the formula of NLR and could be more rational and extensive in the evaluation of PSD. Higher SII generally showed that inflammatory response of patients enhanced and the immune response decreased.

Platelets are not a result of inflammation, but also a predictor of inflammation. Activated platelets increase the risk of cardio-cerebrovascular diseases and mental disorders, including depression. ${ }^{46}$ Inflammation induces dense granules within activated platelets releasing 5-hydroxytryptamine (5-HT) and other proinflammatory molecules such as cytokines, metalloprotein $\mathrm{TF}$, P-selectin, CD40L that play an important role in the occurrence of depression. ${ }^{47}$ In addition, pro-inflammatory factors and activated platelets may have a negative effect on phosphorylation and expression of brain-derived neurotrophic factor (BDNF) and BDNF receptor (TrkB) involved in the pathogenesis of depression. ${ }^{48}$

Our study primarily certified that higher SII was independently associated with higher risk of developing PSD. To diagnose and treat PSD, monitoring their changes over time, regular follow-up of PLR, dNLR, NLR, especially SII may be a cheap, easy and effective strategy for PSD screening and management. High-level SII at admission could give physicians some diagnostic and prognostic clues to detect early PSD for stroke patients, which may lead to a better treatment. This will also help investigate how the immune-inflammatory reaction translates into psychiatric illness promoting our knowledge in the etiopathogenesis of these mental disorders.

This study also had some inevitable limitations. First, it was a single-center study with 423 cases enrolled. Second, we only recorded the SII, NLR, PLR, dNLR once at a time at admission. It is indispensable to take routine blood tests constantly in order to investigate the association of dynamic changes in blood index after stroke. Third, we failed to check the medication history before hospitalization of participants such as Aspirin, which may affect the results.

\section{Conclusion}

In conclusion, higher levels of SII, dNLR, NLR and PLR were associated with an increased prevalence of PSD. At the same time, SII was a more effective indicator superior to other inflammatory of markers in the development of PSD.

\section{Ethics Statement}

This study obtained the approval by the Medical Ethics Committee of the First Affiliated Hospital of Wenzhou Medical University. Patients all signed the written informed consents before participating in our study. The study project conforms to the ethical guidelines of the Declaration of Helsinki. The data was kept confidential and not shared.

\section{Acknowledgments}

We thank all staff members, patients and their families for their support and involvement in the study. Jingjie $\mathrm{Hu}$ and Liuyuan Wang are co-first authors in this study.

\section{Author Contributions}

All authors made substantial contributions to conception and design, acquisition of data, or analysis and interpretation of data; took part in drafting the article or revising it critically for important intellectual content; agreed to submit to the current journal; gave final approval of the version to be published; and agree to be accountable for all aspects of the work.

\section{Funding}

This work was subsidised by the Projects of National Science Foundation of China (No.81873799), the National Key Technology Research and Development Program of the Ministry of Science and Technology of China (grant number:2015BAI13B01) and Wenzhou Municipal Sci-Tech Bureau Program (Y20200421).

\section{Disclosure}

The authors declare that the research was conducted in the absence of any commercial or financial relationships and a potential conflict of interest.

\section{References}

1. Wang YL, Wu D, Liao X, et al. Burden of stroke in China. Int $J \quad$ Stroke. 2007;2(3):211-213. doi:10.1111/j.17474949.2007.00142.x

2. Liu L, Wang D, Wong KS, et al. Stroke and stroke care in China: huge burden, signifcant workload, and a national priority. Stroke. 2011;42 (12):3651-3654. doi:10.1161/STROKEAHA.111.635755

3. Hasan TF, Rabinstein AA, Middlebrooks EH, et al. Diagnosis and management of acute ischemic stroke. Mayo Clinic Proceedings. 2018;93(4):523-538. doi:10.1016/j.mayocp.2018.02.013 
4. Jacquin A, Binquet C, Rouaud O, et al. Post-stroke cognitive impairment: high prevalence and determining factors in a cohort of mild stroke. J Alzheimers Dis. 2014;40(4):1029-1038. doi:10.3233/JAD131580

5. Ayerbe L, Ayis S, Crichton S, Wolfe CD, Rudd AG. The long-term outcomes of depression up to 10 years after stroke; the South London Stroke Register. J Neurol Neurosurg Psychiatry. 2014;85(5):514-521. doi:10.1136/jnnp-2013-306448

6. Ayerbe L, Ayis S, Wolfe CD, Rudd AG. Natural history, predictors and outcomes of depression after stroke: systematic review and meta-analysis, Br. J Psychiatry. 2013;20:214-221.

7. Hackett ML, Pickles K. Part I: frequency of depression after stroke: an updated systematic review and meta- analysis of observational studies. Int J Stroke. 2014;9:1017-1025. doi:10.1111/ijs.12357

8. Hackett ML, Anderson CS. Predictors of depression after stroke: a systematic review of observational studies. Stroke. 2005;36 (10):2296-2301. doi:10.1161/01.STR.0000183622.75135.a4

9. Ferrari F, Villa RF. The neurobiology of depression: an integrated overview from biological theories to clinical evidence. Mol Neurobiol. 2017;54:4847-4865. doi:10.1007/s12035-016-0032-y

10. Chamorro A, Dirnagl U, Urra X, Planas AM. Neuroprotection in acute stroke: targeting excitotoxicity, oxidative and nitrosative stress, and inflammation. Lancet Neurol. 2016;15:869-881. doi:10.1016/ S1474-4422(16)00114-9

11. Chamorro Á, Meisel A, Planas AM, Urra X, van de Beek D, Veltkamp R. The immunology of acute stroke. Nat Rev Neurol. 2012;8:401-410. doi:10.1038/nrneurol.2012.98

12. Gelderblom M, Leypoldt F, Steinbach K, et al. Temporal and spatial dynamics of cerebral immune cell accumulation in stroke. Stroke. 2009;40:1849-1857. doi:10.1161/STROKEAHA.108.534503

13. Chen GY, Nunez G. Sterile inflammation: sensing and reacting to damage. Nat Rev Immunol. 2010;10:826-837. doi:10.1038/nri2873

14. Wen H, Weymann Kristianna K, Wood L, Wang WQ. Inflammatory signaling in post-stroke fatigue and depression. Eur Neurol. 2018;80 (3-4):138-148. doi:10.1159/000494988

15. Su JA, Chou SY, Tsai CS, Hung TH. Cytokine changes in the pathophysiology of post stroke depression. Gen Hosp Psychiatry. 2012;34:35-39. doi:10.1016/j.genhosppsych.2011.09.020

16. Kang HJ, Bae KY, Kim SW, et al. Effects of interleukin-6, interleukin-18, and statin use, evaluated at acute stroke, on post-stroke depression during 1-year followup. Psychoneuroendocrinology. 2016;72:156-160. doi:10.1016/j. psyneuen.2016.07.001

17. Gibney SM, McGuinness B, Prendergast C, Harkin A, Connor TJ. Poly I:C-induced activation of the immune response is accompanied by depression and anxiety-like behaviours, kynurenine pathway activation and reduced BDNF expression. Brain Behav Immun. 2013;28:170-181. doi:10.1016/j.bbi.2012.11.010

18. Kumarasamy C, Sabarimurugan S, Madurantakam RM, et al. Prognostic significance of blood inflammatory biomarkers NLR, PLR, and LMR in cancer-a protocol for systematic review and meta-analysis. Medicine. 2019;98:e14834. doi:10.1097/ MD.0000000000014834

19. Xingxing T, Yudong C, Jia L, et al. Diagnostic and predictive values of inflammatory factors in pathology and survival of patients undergoing total cystectomy. Mediators Inflamm. 2020;2020:9234067. doi: $10.1155 / 2020 / 9234067$

20. Kim H, Jung W, Shin YC, et al. The diagnostic and prognostic values of inflammatory markers in intraductal papillary mucinous neoplasm. HPB (Oxford). 2021. doi:10.1016/j.hpb.2021.04.001

21. Azab B, Zaher M, Weiserbs KF, et al. Usefulness of neutrophil to lymphocyte ratio in predicting short- and long-term mortality after non-ST-elevation myocardial infarction. Am J Cardiol. 2010;106:470-476. doi:10.1016/j.amjcard.2010.03.062
22. Qun S, Tang Y, Sun J, et al. Neutrophil-to-lymphocyte ratio predicts 3-month outcome of acute ischemic stroke. Neurotox Res. 2017;31:444-452. doi:10.1007/s12640-017-9707-z

23. Chen HJ, Luan XQ, Zhao $K$, et al. The association between neutrophil-to-lymphocyte ratio and post-stroke depression. Clin Chim Acta. 2018;486:298-304. doi:10.1016/j.cca.2018.08.026

24. Guiqian H, Huijun C, Qiongzhang W, et al. High platelet-tolymphocyte ratio are associated with post-stroke depression. $J$ Affect Disord. 2019;246:105-111. doi:10.1016/j.jad.2018.12.012

25. Yang YL, Wu CH, Hsu PF, et al. Systemic immune-inflammation index (SII) predicted clinical outcome in patients with coronary artery disease. Eur J Clin Invest. 2020;50:e13230. doi:10.1111/ eci. 13230

26. Zhang Y, Chen B, Wang L, Wang R, Yang X. Systemic immune-inflammation index is a promising noninvasive marker to predict survival of lung cancer: a meta-analysis. Medicine. 2019;98: e13788. doi:10.1097/MD.0000000000013788

27. Hu B, Yang XR, Xu Y, et al. Systemic immune-inflammation index predicts prognosis of patients after curative resection for hepatocellular carcinoma. Clin Cancer Res. 2014;20(23):6212-6222. doi:10.1158/1078-0432.CCR-14-0442

28. Duanlu H, Chunjie W, Yufan L, et al. Systemic immune-inflammation index (SII) but not platelet-albumin-bilirubin (PALBI) grade is associated with severity of acute ischemic stroke (AIS). Int J Neurosci;2020. 1-6. doi:10.1080/00207454.2020.1784166

29. Trifan G, Testai FD. Systemic Immune-Inflammation (SII) index predicts poor outcome after spontaneous supratentorial intracerebral hemorrhage. J Stroke Cerebrovasc Dis. 2020;29:105057. doi:10.1016/j.jstrokecerebrovasdis.2020.105057

30. Mazza MG, De Lorenzo R, Conte C, et al. Anxiety and depression in COVID-19 survivors: role of inflammatory and clinical predictors. Brain Behav Immun. 2020;89:594-600. doi:10.1016/j. bbi.2020.07.037

31. Arteaga-Henríquez G, Simon MS, Burger B, et al. Low-grade inflammation as a predictor of antidepressant and anti-inflammatory therapy response in MDD patients: a systematic review of the literature in combination with an analysis of experimental data collected in the EU-moodinflame consortium. Front Psychiatry. 2019;10:458. doi:10.3389/fpsyt.2019.00458

32. Benedetti F, Aggio V, Pratesi ML, et al. Neuroinflammation in bipolar depression. Front Psychiatry. 2020;11:71. doi:10.3389/ fpsyt.2020.00071

33. Banerjee DD. The other side of COVID-19: impact on obsessive compulsive disorder (OCD) and hoarding. Psychiatry Res. 2020;288:112966. doi:10.1016/j.psychres.2020.112966

34. Hamilton M. A rating scale for depression. J Neurol Neurosurg Psychiatry. 1960;23:56-62. doi:10.1136/jnnp.23.1.56

35. Spalletta G, Bossu P, Ciaramella A, Bria P, Caltagirone C, Robinson RG. The etiology of post stroke depression: a review of the literature and a new hypothesis involving inflammatory cytokines. Mol Psychiatry. 2006;11:984-991. doi:10.1038/sj.mp.4001879

36. Das Jyotirekha G, Rajanikant K. Post stroke depression: the sequelae of cerebral stroke. Neurosci Biobehav Rev. 2018;90:104-114. doi:10.1016/j.neubiorev.2018.04.005

37. Jin R, Yang G, Li G. Inflammatory mechanisms in ischemic stroke: role of inflammatory cells. J Leukoc Biol. 2010;87(5):779-789. doi:10.1189/jlb.1109766

38. Ong CW, Pabisiak PJ, Brilha S, et al. Complex regulation of neutrophil-derived MMP-9 secretion in central nervous system tuberculosis. J Neuroinflammation. 2017;14(1):31. doi:10.1186/ s12974-017-0801-1

39. Amantea D, Nappi G, Bernardi G, et al. Post-ischemic brain damage: pathophysiology and role of inflammatory mediators. FEBS J. 2009;276(1):13-26. doi:10.1111/j.1742-4658.2008.06766.x 
40. Sreeramkumar V, Adrover JM, Ballesteros I, et al. Neutrophils scan for activated platelets to initiate inflammation. Science. 2014;346 (6214):1234-1238. doi:10.1126/science.1256478

41. Yilmaz G, Arumugam TV, Stokes KY, Granger DN. Role of $\mathrm{T}$ lymphocytes and interferon-gamma in ischemic stroke. Circulation. 2006;113(17):2105-2112. doi:10.1161/ CIRCULATIONAHA.105.593046

42. Liu -D-D, Chu S-F, Chen C, et al. Research progress in stroke-induced immunodepression syndrome (SIDS) and stroke-associated pneumonia (SAP). Neurochem Int. 2018;114:42-54. doi:10.1016/j.neuint.2018.01.002

43. Feigenson KA, Kusnecov AW, Silverstein SM. Inflammation and the two-hit hypothesis of schizophrenia. Neurosci Biobehav Rev. 2014;38:72-93.

44. Janssen DG, Caniato RN, Verster JC, Baune BT. A psychoneuroimmunological review on cytokines involved in antidepressant treatment response. Hum Psychopharmacol. 2010;25 (3):201-215. doi:10.1002/hup.1103
45. Tuglu C, Kara SH. Depression, cytokines and immune system. Bull Clin Psychopharmacol. 2003;13:142-150.

46. Gokdemir MT, Karakilcik AZ, Gokdemir GS. Prognostic importance of paraoxonase, arylesterase and mean platelet volume efficiency in acute ischemic stroke. JPakMedAssoc. 2017;67(11):1679-1683.

47. Wachowicz B. Blood Platelet as a Peripheral Cell in Oxidative Stress in Psychiatric Disorders, Studies on Psychiatric Disorders. Springer; 2015:327-353.

48. Cortese GP, Barrientos RM, Maier SF, et al. Aging and a peripheral immune challenge interact to reduce mature brain-derived neurotrophic factor and activation of TrkB, PLC 1, and ERK in hippocampal synaptoneurosomes. J Neurosci. 2011;31(11):4274. doi:10.1523/ JNEUROSCI.5818-10.2011
Clinical Interventions in Aging

\section{Publish your work in this journal}

Clinical Interventions in Aging is an international, peer-reviewed journal focusing on evidence-based reports on the value or lack thereof of treatments intended to prevent or delay the onset of maladaptive correlates of aging in human beings. This journal is indexed on PubMed Central, MedLine, CAS, Scopus and the Elsevier
Dovepress

Bibliographic databases. The manuscript management system is completely online and includes a very quick and fair peer-review system, which is all easy to use. Visit http://www.dovepress.com testimonials.php to read real quotes from published authors. 